\title{
AVALIAÇÃO DA PERCEPÇÃO DE PROPRIETÁRIOS DE CÃES RESIDENTES EM APARTAMENTOS NO MUNICÍPIO DE NITERÓI-RJ SOBRE OS SINAIS DA SÍNDROME DE ANSIEDADE DE SEPARAÇÃO EM ANIMAIS
}

\author{
Guilherme Marques Soares¹, João Telhado², Rita Leal Paixão³
}

\author{
1 USS \\ 2 UFR-RJ \\ 3 UFF \\ Correspondência: Guilherme Soares: gsoaresvet@gmail.com
}

\begin{abstract}
RESUMO: Esta pesquisa constitui um estudo exploratório sobre a percepção de proprietários de cães residentes em apartamento em relação à síndrome de ansiedade de separação em animais (SASA), distúrbio caracterizado por comportamentos anormais exibidos pelos animais quando afastados da figura de apego. A coleta de dados foi realizada por meio de entrevista para avaliar a percepção dos proprietários (EAPP) e dois questionários, o questionário para identificação da SASA (QI-SASA) e um questionário de apoio (QA). Foram entrevistados 161 proprietários de cães residentes em apartamento no município de Niterói-RJ. Concluiu-se que os proprietários percebiam o problema, mas a maioria $(58,7 \%)$ de forma distorcida, atribuindo os comportamentos indesejáveis à pirraça. Concluiu-se também, que a maioria dos proprietários $(75,0 \%)$ relatou que o cão apresentava comportamentos incômodos ou problemas de comportamento, mas somente uma pequena parcela destes $(15,1 \%)$ considerou que tais comportamentos seriam decorrentes de atitudes do próprio proprietário em relação ao cão.
\end{abstract}

Palavras-chave: ansiedade de separação; cães; comportamento; bem-estar animal

\section{EVALUATION OF THE PERCEPTION OF OWNERS OF DOGS THAT LIVE IN APARTMENTS IN NITERÓI, RJ ABOUT THE SEPARATION ANXIETY SYNDROME IN ANIMALS' SIGNALS}

\begin{abstract}
This research is an exploratory research about the perception of the apartment dogs' owners about the Separation Anxiety Syndrome in Animals (SASA), a disease characterized by abnormal behaviors shown by the animals when they were put away from their attached subjects. The data were collected by means of an interview to evaluate the owner's perception (EAPP, from Portuguese: "Entrevista para Avaliar a Percepção do Proprietário"); and two questionnaires: one to identify the SASA and, the other, a Support Questionnaire (QA - from Portuguese: "Questionário de Apoio"). A hundred and sixty-one dogs' owners that live in apartments in the Niterói city (in the Rio de Janeiro state) were interviewed. It was concluded that the owners have noticed the problem, but the majority (58.70\%) in a distorting way, attributing the undesirable behaviors to a kind of 'spite' of the animal. And also the majority of the owners $(75 \%)$ has mentioned that their dog showed inconvenient behaviors or behavior' troubles. But only a small part of them $(15.13 \%)$ has declared that these behaviors were a consequence to the owners themselves' attitude in relation to their dogs.
\end{abstract}

Key Words: separation anxiety, dogs, behavior, animal welfare 


\section{INTRODUÇÃO}

A Síndrome de Ansiedade de Separação em Animais (SASA) é caracterizada nos cães por um conjunto de comportamentos exibidos quando esses animais são deixados sozinhos, sendo um dos problemas comportamentais mais comuns na espécie (Takeuchi et al., 2001). Os comportamentos, que compõem a síndrome, segundo a descrição de vários autores (McCrave, 1991; Fogle, 1992; Overal, 1997; King et al., 2000; Beaver, 2001; Appleby e Pluijmakers, 2003; Bénézech, 2003; Schwartz, 2003; Landsberg et al., 2004; Lantzman, 2006; Soares et al., 2007) são: vocalização excessiva, destruição de objetos, micção e defecação fora do lugar determinado. A síndrome também pode incluir vômitos e depressão (McCrave, 1991; Fogle, 1992; Bénézech, 2003; Landsberg et al., 2004; Lantzman, 2006), além de comportamentos compulsivos (McCrave, 1991; Fogle, 1992; Beaver, 2001; Overall e Dunham, 2002; Landsberg et al., 2004). Os comportamentos compulsivos são movimentos repetidos intensamente e fora de contexto, atribuídos a uma busca na redução de um estado da ansiedade (Fogle, 1992; Telhado, 1997). A SASA é um dos distúrbios de comportamento mais atendidos em todo o mundo em serviços especializados de etologia clínica junto com distúrbios relacionados à agressividade (Overall, 2001; Seksel e Lindeman, 2001; Takeuchi et al., 2001; Denenberg et al., 2005).

A síndrome pode se manifestar na ausência real do proprietário ou outra figura de vínculo, mas também pode ocorrer quando o cão tem o acesso ao proprietário restrito de alguma maneira, como ao ser fica preso em algum cômodo, caixa de transporte ou gaiola, ainda que essa figura de vínculo esteja no mesmo ambiente e a poucos metros do animal (McCrave, 1991; Landsberg et al., 2004).

Os quatro sinais básicos podem ser explicados como tentativas do cão restabelecer contato com a figura de vínculo ausente, como ocorre com a vocalização excessiva e os comportamentos destrutivos. Os comportamentos destrutivos normalmente são direcionados a objetos que tragam referência olfativa da figura de vínculo, como pertences do proprietário, ou direcionados a portas, janelas ou móveis que possam ser usados como rotas de fuga para o cão.

Os casos que apresentam distúrbios de eliminação podem ser considerados mais graves, pois a micção e a defecação caracterizam uma perda do controle da situação por parte do cão. Por teoria, o animal sente-se abandonado por sua matilha e, desistindo da tentativa de fazer contato com a figura de vínculo, passa a deixar marcas para ser encontrado. Caracteriza também uma ativação autonômica parassimpática comum em situações mais intensas de estresse. (Appleby e Pluijmakers, 2003).

Os sinais da SASA são frequentemente associados à pirraça. Os proprietários interpretam tais comportamentos como tentativas de o cão se vingar pelo fato de ter sido deixado sozinho (McCrave, 1991; Appleby e Pluijmakers, 2003).

O presente trabalho objetivou avaliar a percepção dos proprietários em relação à SASA e identificar as principais queixas dos proprietários em relação ao comportamento de seus cães para ratificar se a SASA realmente é uma das principais queixas. Para tal analisou-se aspectos da SASA na busca de meios para prevení-la e tratá-la, pois ela reduz a qualidade de vida dos animais que a apresentam, provoca perdas econômicas aos proprietários pela destruição de seus pertences, traz transtornos ao relacionamento com 

Niterói-RJ sobre os sinais da sindrome de ansiedade de separação em animais

vizinhos) e é causa frequente de abandono e eutanásia de cães.

\section{MATERIAL E MÉTODOS}

A população escolhida foram os cães residentes em apartamentos situados em lcaraí, que é um bairro com características mistas entre residencial e comercial, no Município de Niterói-RJ (latitude 22,52S, longitude 43,0W), onde há predomínio de prédios de apartamentos residenciais. Porém, foram incluídos animais com residência em bairros próximos com características semelhantes. Todas as informações sobre o comportamento dos cães foram colhidas junto aos proprietários.

Foram selecionados seis estabelecimentos que se dedicavam ao comércio de produtos veterinários (medicamentos, cosméticos, rações e acessórios) e ofereciam serviços de banho e tosa. Em tais estabelecimentos, foram abordados aleatoriamente proprietários de cães, no período de julho a novembro de 2006.

O estudo baseou-se em dados obtidos por meio de uma entrevista e de aplicação de questionários. $\mathrm{Na}$ Entrevista para Avaliação da Percepção do Proprietário (EAPP), as respostas eram gravadas para posterior análise. Imediatamente após a entrevista, dois questionários foram entregues ao entrevistado, o questionário para identificação da SASA (QI-SASA) e o outro Questionário de Apoio (QA) para a identificação do proprietário, do animal, do ambiente social e físico, e de alguns itens de manejo do animal. Os respondentes levavam consigo os questionários e devolviam preenchidos posteriormente. Não houve, portanto, qualquer tipo de interferência do entrevistador nas respostas aos questionários.

O QI-SASA é um instrumento validado para avaliação da SASA (Soares et al., 2009).
O proprietário para ser incluído, deveria viver com seu cão e ser residente em apartamento no município de Niterói, no bairro de Icaraí ou outro de características semelhantes. Tais informações foram extraídas do QA, ou seja, dados referentes a alguns proprietários foram excluídos do estudo posteriormente a sua participação.

Para a quantificação dos "problemas de comportamento" ou dos "comportamentos incômodos" mais frequentes, assim como das razões para tais comportamentos e para as "modalidades de pirraça" foram incluídos todos aqueles que responderam à entrevista nos estabelecimentos selecionados, mesmo que não tivessem devolvido os questionários ou que não residissem em apartamentos ou nos bairros determinados.

As perguntas da EAPP (Quadro 1) foram elaboradas de modo a promover uma abordagem gradual ao problema, ou seja, as questões envolviam o problema, inicialmente de forma menos específica e iam se tornando mais direcionadas no decorrer da entrevista. Tal abordagem gradativa visou identificar se o proprietário percebia 0 problema e sua visão sobre o assunto. As últimas perguntas investigavam se o animal tinha alguma enfermidade, a fim de descartar outras possíveis fontes de variação no comportamento do animal, ou associar algum quadro mórbido com a SASA.

Comportamentos específicos foram listados de forma a não permitir que o respondente identificasse o que se pretendia objetivamente com as perguntas do QI-SASA, para que as respostas não fossem direcionadas de maneira a enquadrar seu cão ou não dentro do problema pesquisado. Os dados foram agrupados de forma a caracterizar como positivos aqueles questionários que incluíssem ao menos um dos sinais clássicos da SASA ou 
comportamento depressivo, associados a sinais de hipervinculação.

Foram realizadas 161 entrevistas, porém nove foram descartadas por falhas técnicas na sua realização, totalizando 152 entrevistas válidas. Foram obtidos ao todo 102 conjuntos de QI-SASA e QA que atendiam aos critérios de inclusão.

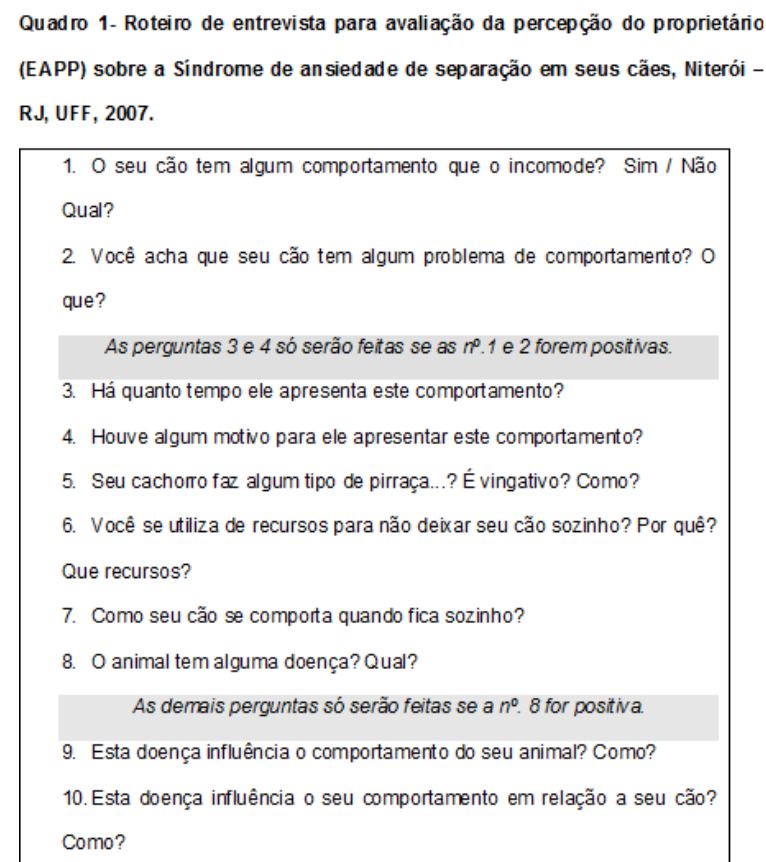

Após a reprodução do áudio e a transcrição literal das respostas, estas foram agrupadas de acordo com seus núcleos significativos e quantificadas com o objetivo de identificar os problemas de comportamento dos quais os proprietários mais se queixavam e suas variáveis.

Os problemas relatados nas perguntas "Seu cão tem algum comportamento que te incomoda?" e "Seu cão tem algum problema de comportamento?' foram agrupados.

As pergunta "Houve algum motivo para ele apresentar este comportamento?" e "Há quanto tempo ele apresenta este comportamento?" não eram feita àqueles proprietários que diziam que seus cães não tinham comportamentos incômodos ou problemas de comportamento.
Outra pergunta feita na entrevista foi se o cão fazia algum tipo de pirraça, pergunta feita propositalmente indutora, já que os autores descrevem tal associação dos sinais da SASA com pirraça.

Para testar os dados categorizados, foi realizado o teste de qui-quadrado clássico $\left(x^{2}\right)$, de acordo com Arango (2005) e através do programa Graphad Instat® V.2.0. O nível de significância para todos os testes aplicados foi de $5 \%(\alpha=0,05)$.

\section{RESULTADOS}

A agressividade foi 0 comportamento incômodo ou problemático mais relatado com $27,6 \%$ das respostas, seguido por vocalizações com $23,0 \%$ e comportamentos sanitários inadequados referentes à micção e defecação em locais e/ou contextos inapropriados (13,8\%). Trinta e oito proprietários (25,0\%) afirmaram que seu cão não apresentava qualquer comportamento incômodo ou problema de comportamento. Portanto 114 proprietários $(75,0 \%)$ consideraram que seus cães apresentavam algum comportamento incômodo ou algum problema de comportamento. Os comportamentos citados foram agrupados de acordo com o relato dos proprietários.

$\mathrm{Na}$ pergunta referente à pirraça, houve $111(73,0 \%)$ respostas positivas, sendo os comportamentos relacionados à micção e defecação os mais citados como pirraça. Foram 43 (28,3\%) aqueles que relataram que seus cães demonstram comportamentos eliminativos inapropriados quando querem fazer pirraça. Os demais comportamentos citados foram comportamentos destrutivos $(17,1 \%)$, agressividade $(9,9 \%)$, teimosia $(6,6 \%)$, vocalizações $(5,9 \%)$, exigências alimentares (o animal só come com determinadas exigências atendidas) 

Niterói-RJ sobre os sinais da sindrome de ansiedade de separação em animais

$(5,9 \%)$, ciúmes $(2,0 \%)$ e "ficar de mal" $(3,3 \%)$. Neste último item o animal permanece por algum tempo ignorando a presença do proprietário ou não atendendo a nenhuma de suas solicitações.

Outra pergunta feita nas entrevistas, que visava identificar se os proprietários reconheciam a origem do problema de comportamento de seus cães, foi a seguinte: "Houve algum motivo para ele apresentar este comportamento?". Os motivos descritos pelos proprietários foram agrupados, sendo o próprio cão incriminado em $25,6 \%$ dos casos como "culpado" pelo seu comportamento, seguido de eventos externos $(20,4 \%)$; inabilidade do proprietário $(15,1 \%)$; a raça $(4,6 \%)$; e $11,2 \%$ desconheciam. Os proprietários que diserram que seus cães não tinham comportamentos incômodos totalizaram $35(23,0 \%)$.

O total de entrevistas para o levantamento dos comportamentos apresentados quando os cães ficavam sozinhos foi de 68. $\mathrm{Na}$ avaliação combinada de entrevistas e questionários, o total de animais que apresentaram sinais de SASA foi de 45 $(65,2 \%)$ dentre os 68 . Valor que não difere significativamente dos $59,2 \%$ encontrados pela análise isolada dos questionários $\left(\mathrm{X}^{2}=0,84 ; \mathrm{GL}=1 ; p=0,179\right)$. Desses quarenta e cinco, sete $(15,6 \%)$ apresentaram histórico de desenvolver os sinais de SASA apenas em determinadas condições, o que passará a ser chamado de SASA Condicional. Quatro relataram que seus cães apresentavam os sinais quando havia mudanças na rotina. Dois, desses sete, disseram que seus cães apresentavam os sinais de SASA se, ao sair, não Ihes forem dadas "satisfações", como o proprietário dizer que iria trabalhar, mesmo quando fosse sair, por exemplo.

O último desses sete, descreveu a mesma apresentação condicional da SASA quando seu cão ficava no escuro.
Apesar da diferenciação apresentada, todos esses casos podem ser atribuídos a mudanças na rotina ou no ritual de partida dos proprietários, que funcionam como desencadeadores dos sinais de SASA.

Observou-se a percepção dos proprietários em relação aos sinais da SASA em seus cães. Na comparação entre EAPP e QI-SASA, 46 proprietários perceberam os sinais, sendo que desses 39 cães apresentaram-se como positivos pela avaliação dos questionários e sete como negativos. Vinte e um respondentes não mostraram perceber o problema.

$\mathrm{O}$ resultado obtido mostrou que os proprietários entrevistados percebiam o problema $\left(x^{2}=23,3 ; \mathrm{GL}=1 ; p<0,0001\right)$, porém dos 46 que percebiam 0 problema, $27(58,7 \%)$ o atribuíram à pirraça e apenas $9(19,6 \%)$ a algum problema de comportamento. Um total de $10,9 \%$ descreveu os sinais como comportamento incômodo e o mesmo número como motivo para não deixar o cão sozinho em casa.

Os 21 proprietários que não perceberam 0 problema foram comparados com os resultados da avaliação dos QI-SASA e os sinais de SASA extraídos desses questionários foram: oito com vocalização excessiva; sete com comportamento depressivo; cinco com comportamento destrutivo; e um com eliminação inapropriada. Contrariando a expectativa de que a não percepção do problema pudesse ser devida a comportamentos depressivos, já que esses são silenciosos.

\section{DISCUSSÃO}

Duas dificuldades acompanham qualquer pesquisa sobre problemas de comportamento relacionados à ansiedade em animais. Não há um padrão que determine o que é cada doença, como há o DSM-IV (Diagnostic and Statistical Manual for Mental 
Disorders, $4^{\underline{a}}$ versão) para a psiquiatria humana. O segundo obstáculo é a dificuldade de definir qualquer problema de comportamento como positivo ou negativo, já que não há distúrbio psiquiátrico que seja binário em qualquer espécie animal É importante ressaltar que nada substitui uma abordagem minuciosa e individualizada de cada caso, considerando cada particularidade dos agentes da relação (humanos e caninos), que, ainda assim é insuficiente para mensurar o real sofrimento dos animais ao serem deixados sozinhos por seus proprietários.

Houve uma tendência maior a atribuir ao cão as razões para os comportamentos incômodos ou para os problemas de comportamento apresentados. Apenas 15,1\% dos proprietários admitiram que tais problemas ocorreram por inabilidade deles em lidar com o cão ou porque o cão aprendeu com eles a se comportar assim. Tal dado corrobora com vários autores que descrevem que a maioria dos problemas de comportamento dos cães é causada ou agravada pela forma com que o proprietário conduz esse animal (O'Farrell, 1997; Overall, 1997; Bénézech, 2003; Kobelt et al., 2003; Ladewig, 2005; Bennett e Rohlf, 2007).

Faz-se importante ressaltar que, por definição, pirraça é um ato praticado propositalmente com 0 intuito de contrariar, aborrecer, agastar ou amolar alguém (Ferreira, 1975). Sendo desconhecida nos cães essa capacidade de praticar atos premeditados com o intuito de contrariar ou aborrecer quem quer que seja, sugere-se que sejam atitudes inconvenientes para o proprietário, que visam comunicar algo normalmente não entendido pelo mesmo (Fogle, 1992; Beaver, 2001). O cão também é capaz de se comportar de maneiras inconvenientes apenas para chamar a atenção do proprietário (attention seeking behavior) (Fogle, 1992; Overall, 1997; Beaver, 2001; Landsberg et al., 2004). Para isto, o repertório comportamental pode ser variado, dependendo do comportamento do proprietário o cão pode vocalizar excessivamente, urinar/defecar em locais impróprios e até simular dores. Existem também comportamentos exibidos pelo cão na ausência do proprietário e que este pode atribuir à pirraça. Contudo, são comportamentos lúdicos (roer objetos, cavar buracos, etc) e/ou sanitários não apresentados pelo cão com o proprietário presente por saber que este o repreenderá, mas que não encontram obstáculos quando 0 proprietário se encontra distante. Esses comportamentos são encarados como falha na educação do cão (Fogle, 1992; Overall, 1997; Beaver, 2001; Landsberg et al., 2004).

Durante a realização das entrevistas percebeu-se a presença de uma determinada característica pouco citada pela maioria dos autores consultados, claramente descrita apenas por Landsberg e colaboradores (2004), que é o fato do animal apenas apresentar os sinais de SASA em determinadas circunstâncias, não os apresentando quando deixados sozinhos nas demais.

O aspecto condicional da SASA pode induzir ao erro de diagnóstico, pois, em virtude do animal não se comportar sempre da mesma maneira descarta-se a opção da SASA. Porém, como foi observado, aproximadamente $15 \%$ dos animais que apresentaram SASA o fizeram apenas sob certas condições sem, com isso, descartar o diagnóstico de SASA.

Se a condição desencadeante puder ser evitada, é certo que o impacto da SASA na qualidade de vida do cão e da família é menor, porém pode gerar certos rituais ou impedimentos que podem desencadear outros fatores 

Niterói-RJ sobre os sinais da sindrome de ansiedade de separação em animais

redutores na qualidade de vida de todos.

O fato de a SASA ser percebida como pirraça, possivelmente gera uma instabilidade na relação entre o cão e o proprietário. A partir do momento que tal atitude é encarada como proposital, leva o proprietário a punir o cão e/ou a sentir aversão a ele, para não falar em raiva ou ódio, com posterior degradação da relação e agravamento do problema.

\section{CONCLUSÃO}

A maioria dos proprietários dos e cães considerados positivos para SASA neste estudo perceberam o problema, porém o fizeram de maneira distorcida antropomorfizada, atribuindo os comportamentos característicos à síndrome como pirraça. Além dos cães com sinais compatíveis com a SASA, os comportamentos mais relatados como incômodos ou problemáticos foram a agressividade e as vocalizações excessivas. Ambos os resultados obtidos ressaltam a importância de que os Médicos Veterinários que atendem a cães, principalmente nos grandes centros urbanos, tenham conhecimento sobre os distúrbios de comportamento para orientar corretamente os proprietários desses cães.

\section{AGRADECIMENTOS}

A todos aqueles que com muito
boa vontade responderam às
entrevistas e aos questionários.
Também aos empresários que
permitiram que a pesquisa fosse
realizada em seus estabelecimentos.
Esta pesquisa teve o apoio da CAPES
através do fornecimento de bolsa de
mestrado.

\section{NOTAS INFORMATIVAS}

De acordo com a Resolução 196/96 do Conselho Nacional de Saúde (CNS), vinculado ao Ministério da Saúde/BR, o projeto foi submetido e aprovado pelo Comitê de Ética em Pesquisa da Faculdade de Medicina da Universidade Federal Fluminense (CEP CMM/HUAP no. 149/06). Cada participante, ao ser abordado, assinou um termo de consentimento livre $e$ esclarecido.

\section{REFERÊNCIAS}

APPLEBY, D.; PLUIJMAKERS, J. Separation anxiety in dogs: The function of homeostasis in its development and treatment, Veterinary Clinics of North America: Small Animal Practice, v. 33, n. 2, p. 321-344, 2003.

ARANGO, G. H. Bioestatística: teórica e computacional. 2. ed. Rio de Janeiro: Guanabara Koogan, 2005.

BEAVER, B. V. Comportamento Canino: um guia para veterinários. São Paulo: Roca, 2001.

BENNETT, P. L.; ROHLF, V. I. Ownercompanion dog interactions: Relationships between demographic variables, potentially problematic behaviours, training engagement and shared activities, Applied Animal

Behaviour Science, v. 102, n.1-2, p. 65-84, 2007.

BENEZECH, M. L'homme et le chien domestique: une pathologie neuropsychiatrique commune?, Annales Médico Psychologique, v. 161, n. 8, p. 569-578, 2003.

DENENBERG, S.; LANDSBERG, G. M.; HORWITZ, D.; SEKSEL, K. A Comparison of Cases Referred to Behaviorists in Three Different Countries, in: MILLS, D.; LEVINE, E.; LANDSBERG, G. et al., J. Current Issues and Research in Veterinary Behavioral Medicine: Papers Presented at the 5th International Veterinary Behavior Meeting, Indiana: Purdue University Press, 2005, p.56-62. 
FERREIRA, A. B. H. Novo Dicionário da Língua Portuguesa, Rio de Janeiro: Editora Nova Fronteira, 1975.

FOGLE, B. The Dog's Mind. London: Pelham Books, 1992.

KING, J. N.; SIMPSON, B. S.; OVERALL, K. L.; APPLEBY, D. et al.. Treatment of separation anxiety in dogs with Clomipramina: results from a prospective, randomized, double-blind, placebocontrolled, parallel-group, mullticenter clinical trial, Applied Animal Behaviour Science v. 67, n. 4, p. 255-275, 2000.

KOBELT, A. J.; HEMSWORTH, P. H.; BARNETT, J. L. et al.. A survey of dog ownership in suburban Australia-conditions and behaviour problems, Applied Animal

Behaviour Science, v. 82, n. 3, p. 137-148, 2003.

LADEWIG, J. Of mice and men: Improved welfare through clinical ethology, Applied Animal Behaviour Science, v. 92, n. 3, p. 183192, 2005.

LANDSBERG, G.; HUNTHAUSEN, W.; ACKERMAN, L. Problemas Comportamentais do Cão e do Gato. 2 ed., São Paulo: Roca, 2004.

LANTZMAN, M. Ansiedade de Separação em Cães, disponível em: $<h t t p: / / w w w . p e t . v e t . b r / a n s i e d a d e . h t m>$. Acesso em 13 janeiro 2006.

MCCRAVE, E. A. Diagnostic criteria for separation anxiety in the dog, Veterinary Clinics of North America: Small Animal Practice, v. 21, p.247-256, 1991.

O'FARRELL, V. Owner attitudes and dog behaviour problems, Applied Animal Behaviour Science, v. 52, p. 205-213, 1997.

OVERALL, K. L. Clinical behavioral medicine for small animals, St. Louis - Missouri: Mosby Year Book, 1997.

OVERALL, K. L. Pharmacological Treatment in Behavioural Medicine: The Importance of Neurochemistry, Molecular Biology and Mechanistic Hypotheses, The Veterinary Journal, v. 162, n. 1, p. 9-23, 2001.

OVERALL, K. L.; DUNHAM, A. Clinical features and outcome in dogs and cats with obsessivecompulsive disorder: 126 cases, Journal of
American Veterinary Medical Association, v. 221, n. 10, p. 1445-1451, 2002.

SCHWARTZ, S. Separation anxiety syndrome in dogs and cats, Journal of American Veterinary Medical Association v. 222, n. 11, p.15261532, 2003.

SEKSEL, K.; LINDEMAN, M. J. Use of clomipramine in treatment of obsessivecompulsive disorder, separation anxiety and noise phobia in dogs: a preliminary, clinical study, Australian Veterinary Journal, v. 79, n. 4, p. 252-256, 2001.

SOARES, G. M.; TELHADO, J. ; PAIXÃO, R. L. Ansiedade de Separação e suas implicações na qualidade de vida de cães domésticos (Canis familiaris), Revista Clínica Veterinária, n. 67, p. 76-82, 2007.

SOARES, G. M.; TELHADO, J. ; PAIXÃO, R. L. Construção e validação de um questionário para identificação da Síndrome de Ansiedade de Separação em Cães domésticos, Ciência Rural, v.39, n.3, p.778-784, 2009.

TAKEUCHI, Y.; OGATA, N.; HOUPT, K. A.; SCARLETT, J. M. Differences in background and outcome of three behavior problems of dogs, Journal of American Veterinary Medical Association, v. 70, p. 297-308, 2001.

TELHADO, J. Contribuição ao estudo de dermatite de lambedura em cães. São Paulo, 1996. 140f. Tese (Doutorado) - Faculdade de Medicina Veterinária e Zootecnia, Universidade de São Paulo, São Paulo, 1997. 